\title{
MATHEMATICAL SKILLS OF PRIMARY SCHOOL CHILDREN IN CONTEXT OF THEIR MOTOR SKILLS
}

\author{
Zdeněk Rechtik $^{1 *}$, Ludmila Miklánková ${ }^{2}$, Michaela Pugnerová $^{3}$, Alena Navátilová ${ }^{4}$ \\ ${ }^{1}$ Mr., Department of Primary and Pre-primary Education, Faculty of Education, Palacky University \\ in Olomouc, CZECH REPUBLIC, email: zdenek.rechtik@upol.cz \\ ${ }^{2}$ Assoc. Prof., Department of Primary and Pre-primary Education, Faculty of Education, Palacky \\ University in Olomouc, CZECH REPUBLIC, email: ludmila.miklankova@upol.cz \\ ${ }^{3}$ Dr. Department of Psychology and Abnormal Psychology, Faculty of Education, Palacky \\ University in Olomouc, CZECH REPUBLIC, email: michaela.pugnerova@upol.cz \\ ${ }^{4}$ Ms., Department of Primary and Pre-primary Education, Faculty of Education, Palacky University \\ in Olomouc, CZECH REPUBLIC, email: alinavratilova@email.cz \\ ${ }^{*}$ Corresponding Author
}

\begin{abstract}
Some researchers suggest a link between motor skill levels and academic achievement. Therefore, this research focuses on assessing the effect of motor skills on children's mathematical skills. The aim of the research is to explore and analyze relationship between mathematical skills and the level of motor skills in children attending primary schools in the Czech Republic. Confirmation of mentioned relationship could lead to improved position of school physical education, higher focus on well-performed motor skills and aimed intervention. Within the research were asked following questions: Is there a relationship between mathematical skills and the level of motor skills in children attending primary education? Are there gender differences in the monitored skills (mathematical or motor)? The research group consisted of 75 children in average age $9.48 \pm 0.75$ years. The level of motor skills was monitored by MABC-2 test battery. The cognitive ability test (CAT) was used to determine level of mathematical skills in children. Data were assessed by correlation analysis. Gender differences data were detected by t-test. Results were obtained within the project IGA_PdF_2021_017. The research results indicate gender differences in some of motor skills subtests, but not in the overall levels of motor skills. Significant differences were found in the level of mathematical skills in children, where girls achieved better results $(p \leq 0,01)$. Statistical analysis also confirmed some correlations between mathematical skills and some motor skills subtests. Although the research results revealed only weak or moderate correlations between the mathematical skills and some motor skills, further research implemented on larger group of primary-aged children is necessary for better understanding of this topic. Important thing is not to neglect the role of school physical education as it may affect academic achievement in children through improved mathematical skills.
\end{abstract}

Keywords: mathematics, motor skills, primary children.

\section{INTRODUCTION}

The relationship between motor skills and cognitive development in children not only in primary schools has been researched recently worldwide (Gu, Zhang, Lun (Alan) Chu, Zhang \& Thomas Thomas, 2019; Gonzalez, Alvarez \& Nelson, 2019; Souto et al. 2020). This issue is viewed from several possible angles. This issue is often researched in connection with the child's school maturity and the beginning of compulsory school attendance. We believe that, especially with regard to foreign research, it is important to examine this issue in more depth in the Czech Republic as well. Czech compulsory school attendance on the lower level of primary schools is divided into two educational periods $\left(1^{\text {st }}\right.$ period from first grade to third grade and $2^{\text {nd }}$ 
period is fourth and fifth grade). And thus contribute to the deepening the knowledge about this issue. Therefore, we intend to explore the partition period between mentioned educational periods. In the context of education, educational psychology in particular deals with the cognitive development and related cognitive abilities of children. The basic concept in psychology is man, his life and development (Čáp, 1992). We consider important to look at the teaching process comprehensively, ie not only from the pedagogical point of view, but also from the point of view of pedagogical psychology. If we know the cognitive specificities and basic cognitive development of children, we can also choose adequate educational aim, forms, methods and other elements necessary for an effective teaching process. Results from international research in younger school-aged children revealed that motor skills affect cognitive abilities in various aspects (Cadoret et al., 2018; Macdonald, Milne, Orr \& Pope, 2018; Engel, Broderick, van Doorn, Hardy, Parmenter, 2018; Zeng, Johnson, Boles \& Bellows, 2019; Gudmundsson \& Gretarsson, 2011). Macdonald, Milne, Orr, and Pope (2018) found that fine motor skills were significantly and positively associated with school performance in mathematics and reading, especially in the early years of compulsory school attendance. Significant positive associations were also evident between school success and gross motor skills, specifically upper limb coordination and overall gross motor score. The same authors further suggest that there are only a small number of experimental studies that confirm that motor skills interventions in primary school environment can have a positive impact on school success. Authors Kakebeeke et al. (2019) also deal with the study on gross motor skills in children, but in their approach they focused only on the evaluation of balance. Some authors use the variant where they evaluate gross motor skills according to locomotor and handling skills (Brusseau, Hannon, Fu, Fang, Nam, Goodrum, Burns, 2018; Webster, Martin, Staiano, 2019; Niemistö, Finni, Haapala, Cantell, Korhonen a Sääkslahti, 2019). We decided to combine these two approaches.

One of the partial aims is to examine gender differences in individual categories (motor skills, mathematical skills). Research by Eather, Bull, Young, Barnes, Pollock and Morgan (2018), who confirmed that girls in primary school do not perform as well as boys, also speaks for the study of these differences in motor skills, more precisely handling skills. This is also the reason why we decided to examine this issue more comprehensively in the conditions of Czech education. Maurer and Roebers (2019) found that only adequately difficult motor tasks correlated significantly with the executive functions of young school-age children. This finding is especially important to us, because the challenges and requirements associated with various motor tasks could affect the relationship between motor skills and executive functions. In this introductory part we want also mention, that all above written relationships could now be influenced by covid19 pandemic situation in Czech Republic, where primary schools were closed for almost a year. Therefore also organized physical activities were restricted and limited to a minimum or performed only on-line. So there was no group exercise primarily and many lessons (if any) were only individual and by webcams. Czech Ministry of Education and Sport reacted on this situation by revision of existing Educational Framework Curriculum for Primary Education in January 2021. This change did not affected physical education neither educational area Human and his/her health, where physical education belongs. Mentioned change from January 2021 only adds digital competencies to curriculum. However, at least one point we want to cite, because it deals with children's health. Within mastering digital competencies, children should prevent situations endangering the security of equipment and data, situations with a negative impact on their physical and mental health as well as the health of others (RVP ZV, 2021). We think it is a shame, that no updates were done in the area of physical education. There is probably prediction, that there will not be school closures again, because if so, another time without practising skills under expert supervision (teachers, coaches, etc.) might negatively affect children's motor skills and probably also the other mention areas. Further researches, mainly in recent time horizon should follow, in case some intervention. Many authors suggest, that not only intervention can affect child's motor skills in positive way (Veldman, Jones, Okely, 2016; Golding, Emmett, lles-Caven, Steer \& Lingam, 2014; Bonvin, Barral, Kakebeeke et al., 2012; Johnstone, Hughes, Martin, et al., 2018).

\subsection{Purpose of the Study}

The aim of the research is to explore and analyze relationship between mathematical skills and the level of motor skills in children attending primary schools in the Czech Republic. Confirmation of mentioned relationship could lead to improved position of school physical education, higher focus on well-performed motor skills and aimed intervention.

\subsection{Research Questions}

Within the research and based on mentioned literature we came up with following research questions:

Is there a relationship between mathematical skills and the level of motor skills in children attending primary 
education?

Are there gender differences in the monitored skills (mathematical or motor)?

\section{METHODOLOGY}

The research group consisted of 75 children in average age $9.48 \pm 0.75$ years, who attend primary schools in the Czech Republic. We assessed the differences in the level of mathematical and motor skills. None of the children was obese or had any other disability. Children with physical and other neurological disabilities were not tested. The level of motor skills was monitored by MABC-2 test battery (Henderson, Sugden, \& Barnett, 2007; Czech version by Psotta, 2014). The test battery is designed to evaluate the level of motor skills, respectively motor development. When evaluating basic motor functions, it is assumed that their level is reflected in the output performance and the way of performing sensorimotor tasks. The test contains eight items - movement tasks. Each item is intended to assess one of the following components of motor competence: a manual skill component (fine motor skills), a gross motor component and a balance component. Manual dexterity tests are based on pin placement (MD 1), lacing (MD 2) and drawing a path (MD 3) subtests. Tests focused on gross motor skills include subtests of catching with both hands (AC 1) and throwing a small bag on the mat (i.e. throwing at the target) (AC 2). Tests aimed on balance monitor the balance on the balance board (Bal1), walking forward with the heel touching the toe of the other foot (Bal 2) and hops on the mats (Bal 3). These sub-items are evaluated in accordance with the manual for the administration of the test battery. Test performance scores and conversion of raw score to standard score (SS) were assessed according to the MABC-2 Examiner's Manual (Henderson et al., 2007). The cognitive ability test (CAT) (Thorndike \& Hagen, 1998, Czech version Vonkomer \& Jílek, 1998) was used to determine mathematical skills level. The test is intended for children from 7.6 to 15.9 years of age. The test allows the assessment of an individual's individual ability to work with symbols representing quantities (a quantitative component, contains 3 subtests). The overall profile expressing the level of cognitive abilities of the child is composed of verbal, quantitative and non-verbal areas. To meet the objectives of the research, a part monitoring the level of mathematical skills of the child was used. For the research group was used test variant $\mathrm{C}$ for children aged 9.6 to 11.3 years. The achieved gross score (number of correct answers) is converted according to the child's age into the standard age score. Data were assessed by correlation analysis. Gender differences data were detected by t-test. Results were obtained within the project IGA_PdF_2021_017. The so-called Informed consent was submitted to the legal representatives of the children, where they were introduced to the aims and realization of the research investigation and the anonymity of the data was guaranteed. With mentioned signed consent, the child was included in the research. Participation in the research was free of charge. During the research, the children could withdraw from the research at any time. In case of questions, they were answered in a form appropriate to child's age. The relationship between the level of mathematical skills and the level of motor skills was assessed by correlation analysis. Gender specificity was assessed by t-test.

\section{RESULTS}

We assessed primarily the mathematical skills of children (Tab. 1) in overall and also according to gender groups. In the first subtest the research group achieved $18,44 \pm 3,08$ points in average. The results indicate that boys were more successful in the first subtest, which focused on quantity, more precisely on assessment if there is more, less or even numbers, values (time or money etc.) or graphically expressed values. In the other two subtests were girls better and they also achieved significantly better results in the third subtest $(p \geq 0,01)$. This subtest focuses on numerical lines, more precisely it is add one out with numbers. So it is strongly connected with logical thinking and knowledge from mathematics (multiplication, division, summation, etc.) The average points for the second subtest of the research group is $15,48 \pm 3,70$. In the last, third, subtest achieved the research group 10,96 $\pm 3,22$ points in average. Statistical analysis also revealed statistical significance in the overall level of mathematical skills level between genders $(p \geq 0,01)$. The research group achieved 103,65 $\pm 13,28$ points in standard age score of the mathematics battery.

Tab. 1: The level of mathematical skills of researched children $(n=75)$

\begin{tabular}{|l|c|c|c|c|c|c|}
\hline Variables & $\begin{array}{c}\text { Average } \\
\text { overall }\end{array}$ & $\begin{array}{c}\text { Average } \\
\text { boys }\end{array}$ & $\begin{array}{c}\text { Average } \\
\text { girls }\end{array}$ & $\begin{array}{c}\text { Standard } \\
\text { deviation } \\
\text { overall }\end{array}$ & $\begin{array}{c}\text { Standard } \\
\text { deviation } \\
\text { boys }\end{array}$ & $\begin{array}{c}\text { Standard } \\
\text { deviation } \\
\text { girls }\end{array}$ \\
\hline P1 & 18,44 & 18,72 & 18,18 & 3,08 & 3,10 & 3,07 \\
\hline
\end{tabular}




\begin{tabular}{|l|c|c|c|c|c|c|} 
P2 & 15,48 & 15,17 & 15,77 & 3,70 & 4,05 & 3,36 \\
\hline P3 & 10,96 & 9,86 & 11,97 & 3,22 & 3,62 & 2,44 \\
\hline P_HSO & 44,88 & 43,75 & 45,92 & 8,07 & 9,17 & 6,86 \\
\hline P_SVS & 103,65 & 99,50 & 107,49 & 13,28 & 15,57 & 9,41 \\
\hline
\end{tabular}

Legende: P1: mathematical battery subtest $1, \mathrm{P} 2$ : mathematical battery subtest $2, \mathrm{O} 3$ : mathematical battery subtest 3, P_HSO: rough score of the mathematics battery, P_SVS: standard age score of the mathematics battery

In the further investigation we focused on motor skills (Tab. 2). We assessed 3 parts of motor skills. The first one was fine motor skills, represented by manipulative skills (ManD_SS). The average achieved score for the whole research group was $10,29 \pm 3,14$. Girls performed better than boys but the results were not significant according to the manual. In the second subtest was assessed children's skills in throwing and catching, which are part of gross motor skills. The research group scored in average 8,97 $\pm 2,63$ standard score. Boys achieved better result in gross motor standard score, but the results were not significant. The third component monitored balance skills. The average standard score for the whole research group was $10,01 \pm 2,00$. This time were girls more successful than boys. The overall test score achieved by the research group is $72,77 \pm 14,94$ in average. This results means, than in average are the children in the highest range. That means no motor deficiencies. If the range is between 62 and 70 points it might signalize motor skills problems and there should follow another monitoring. In this category was found 7 children. Alarming finding is, that in third zone ( $\leq 61)$ were 20 children from the research group. This category signalize significant motor deficiencies and should be done specialized examination. The research results indicate gender differences in some of motor skills subtests, but not in the overall levels of motor skills. Although girls have higher score in overall test score, boys achieved significantly better results in catching with both hand subtest $(p \geq 0,01)$, where they scored in average 10,69 $\pm 2,14$, while girls scored $8,92 \pm 2,89$ in average. But girls achieved significantly better results in balance on one leg subtest, more precisely in balance on nondominant leg $(p \geq 0,02)$, where they achieved in average $9,70 \pm 1,95$ rough score and boys only 8,53 $\pm 2,38$.

Tab. 2: The level of motor skills of researched children $(n=75)$

\begin{tabular}{|l|c|c|c|c|c|c|}
\hline Variables & $\begin{array}{c}\text { Average } \\
\text { overall }\end{array}$ & $\begin{array}{c}\text { Average } \\
\text { boys }\end{array}$ & $\begin{array}{c}\text { Average } \\
\text { girls }\end{array}$ & $\begin{array}{c}\text { Standard } \\
\text { deviation } \\
\text { overall }\end{array}$ & $\begin{array}{c}\text { Standard } \\
\text { deviation } \\
\text { boys }\end{array}$ & $\begin{array}{c}\text { Standard } \\
\text { deviation } \\
\text { girls }\end{array}$ \\
\hline ManD_SS & 10,29 & 9,81 & 10,74 & 3,14 & 3,31 & 2,94 \\
\hline AC_SS & 8,97 & 9,36 & 8,62 & 2,63 & 2,43 & 2,78 \\
\hline BAL_SS & 10,01 & 9,61 & 10,38 & 2,00 & 1,98 & 1,97 \\
\hline CTS_SS & 9,65 & 9,47 & 9,82 & 2,42 & 2,57 & 2,30 \\
\hline
\end{tabular}

Legende: ManD_SS: standard score of fine motor skills, AC_SS: standard score of gross motor skills, BAL_SS: standard score of balance skills, CTS_SS: standard score of overall test.

The crucial for our research was the question if there is a relationship between mathematical skills and the level of motor skills in children attending primary education. The significant correlation was not found between the overall test score in motor skills and standard age score in mathematical skills on the significance level $p \leq 0,05$. But standard average score in mathematical skills correlated significantly with fine motor skills $(r s=-0,23)$. Standard average score in mathematical skills also significantly correlated with throwing subtest $(r s=0,23)$, balance on non-prefered leg $(r s=0,33)$ and hopping on mats $(r s=-0,24)$. No significant correlations were found between mathematical skills and motor skills subtest in boys. But in the group of girls was found significant correlation between overall test score in motor skills and mathematical skills subtest number 3 ( $r s=-0,34)$, which is aimed on operation with numbers and mathematical signs (plus, minus, etc.). Simply said it is more complicated subtest number two - there is also a line of numbers and 
mathematical signs and by its combination, children should achieve given result.

\section{RECOMMENDATIONS AND CONCLUSIONS}

Based on the research of Brusseau et al. (2018), who found statistically significant age $\times$ time and sex $\times$ time interactions, suggesting relative greater improvements over time in gross motor scores in older children and in boys. We can also assume, given lower levels of overall motor score in boys, that after aimed intervention boys could achieve greater progress in learning and higher levels of achieved motor skills than girls. In research of Quitério et al. (2018) boys presented higher object movement motor competence than girls while girls were more proficient among self-movement skills. On "total motor competence," boys averaged one point ahead of girls. This results is in opposition to our finding that girls perform better than boys in overall motor competence, but we can see, that both results were not significant. In the study of Herrmann, Heim, \& Seelig (2019) boys performed better on object control, whereas girls achieved better results in locomotion. We can see, that trend is, that boys had better and worse areas and the same is for girls. Usually girls are more skilled in manipulation with their own body, while boys are more skilled in manipulation with objects, but more specifically with bigger muscle groups. Our research confirmed that girls are better in movements, which needs precise moves (fine motor skills - placing pins and fitting needle into gaps). But we rather explored ties between mathematical skills and motor skills. In this case statistical analysis confirmed some correlations between mathematical skills and some motor skills subtests. But not between overall motor scores. Although the research results revealed only weak or moderate correlations between the mathematical skills and some motor skills, further research implemented on larger group of primary-aged children is necessary for better understanding of this topic. And it must be noted and taken in mind, that thanks to covid-19 pandemic situation not only in Czech Republic and all fears connected to it, it was hard and complicated to gather at least some research group. Therefore our research group is rather small and the results of the research cannot be generalized. Nevertheless, we can assume that further research, especially after pandemic situation, on bigger research group should follow and can also bring up some important findings, that can influence educational reality. Not only directly in primary schools in terms of higher focus in fundamental motor skills development and movement precision. But those expected results could also affect pre-gradual education of future primary school teachers with link to mentioned updated Educational Framework Curriculum for Primary Education.

\section{REFERENCE LIST}

Bonvin, A., Barral, J., Kakebeeke, T.H. et al. (2012). Weight status and gender-related differences in motor skills and in child care - based physical activity in young children. BMC Pediatr 12(23). https://doi.org/10.1186/1471-2431-12-23.

Brusseau, T.A., Hannon, J.C., Fu, Y., Fang, Y., Nam, K., Goodrum, S. \& Burns R.D. (2018). Trends in physical activity, health-related fitness, and gross motor skills in children during a two-year comprehensive school physical activity program. J Sci Med Sport, 21(8), 828-832. DOI: 10.1016/j.jsams.2017.12.015.

Cadoret, G., Bigras, N., Duval, S., Lemay, L., Tremblay, T., \& Lemire, J. (2018). The mediating role of cognitive ability on the relationship between motor proficiency and early academic achievement in children. Hum Mov Sci, 57, 149-157. DOI: 10.1016/j.humov.2017.12.002.

Čáp, Jan. (1993). Psychologie výchovy a vyučování. Praha: Karolinum. ISBN 80-7066-534-3.

Eather, N., Bull, A., Young, M.D., Barnes, A.T., Pollock, E.R., \& Morgan, P.J. (2018). Fundamental movement skills: Where do girls fall short? A novel investigation of object-control skill execution in primary-school aged girls. Prev Med Rep, 18(11), 191-195. DOI: 10.1016/j.pmedr.2018.06.005.

Engel, A.C., Broderick, C.R., Van Doorn, N., Hardy, L.L., Parmenter, B.J. (2018). Exploring the Relationship Between Fundamental Motor Skill Interventions and Physical Activity Levels in Children: A Systematic Review and Meta-analysis. Sports Med, 48(8), 1845-1857. DOI: 10.1007/s40279-018-0923-3.

Golding, J., Emmett, P., Iles-Caven, Y., Steer, C., \& Lingam, R. (2014). A Review of Environmental Contributions to Childhood Motor Skills. Journal of Child Neurology, 29(11), 1531-1547. https://doi.org/10.1177/0883073813507483 
Gonzalez, S.L., Alvarez, V. \& Nelson, E.L. (2019). Do Gross and Fine Motor Skills Differentially Contribute to Language Outcomes? A Systematic Review. Front. Psychol. 10. doi: 10.3389/fpsyg.2019.02670

Gu, X., Zhang, T., Lun (Alan) Chu, T., Zhang, X., \& Thomas Thomas, K. (2019). Do Physically Literate Adolescents Have Better Academic Performance? Perceptual and Motor Skills, 126(4), 585-602. https://doi.org/10.1177/0031512519845274

Gudmundsson, E. \& Gretarsson, S. (2012). Mothers' questionnaire of preschoolers' language and motor skills: A validation study. Child: care, health and development, 2012, 39. DOI: 10.1111/j.13652214.2011.01362.x.

Herrmann C, Heim C, \& Seelig H. (2019). Construct and correlates of basic motor competencies in primary school-aged children. J Sport Health Sci, 63.70.

Hidelbrando, P.S.S., Santos, J.N., Leite, H.R., Hadders-Algra, M., Guedes, S.C., Juliana Nogueira Pontes Nobre, Lívia Rodrigues Santos \& Rosane Luzia de Souza Morais (2020). Tablet Use in Young Children is Associated with Advanced Fine Motor Skills, Journal of Motor Behavior, 52(2), 196-203, DOI: $10.1080 / 00222895.2019 .1602505$

Johnstone, A., Hughes, A.R., Martin, A. et al. (2018). Utilising active play interventions to promote physical activity and improve fundamental movement skills in children: a systematic review and meta-analysis. BMC Public Health, 18, 789. https://doi.org/10.1186/s12889-018-5687-z.

Kakebeeke, T.H., Chaouch, A., Knaier, E., Caflisch, J., Rousson, V., Largo, R.H. \& O.G. Jenni. (2019). A quick and qualitative assessment of gross motor development in preschool children. Eur $J$ Pediatr, 178(4), 565-573. DOI: 10.1007/s00431-019-03327-6.

Macdonald, K., Milne, N., Orr, R. \& R. Pope. (2018). Relationships Between Motor Proficiency and Academic Performance in Mathematics and Reading in School-Aged Children and Adolescents: A Systematic Review. International journal of environmental research and public health, 15(8). DOI: https://doi.org/10.3390/ijerph15081603

Maurer, M. N. \& C.M. Roebers. (2019). Towards a better understanding of the association between motor skills and executive functions in 5- to 6-year-olds: The impact of motor task difficulty. Human movement science, 66, 607-620. DOI: https://doi.org/10.1016/j.humov.2019.06.010.

Nan, Z., Johnson, S.L., Boles, R.E., \& Bellows, L.L. (2019). Social-ecological correlates of fundamental movement skills in young children, Journal of Sport and Health Science, 8(2), 122-129. ISSN 20952546.

Niemistö, D., Finni, T., Haapala, E. A., Cantell, M., Korhonen, E. \& A. Sääkslahti. (2019). Environmental Correlates of Motor Competence in Children-The Skilled Kids Study. International journal of environmental research and public health, 16(11). Dostupné z: https://doi.org/10.3390/ijerph16111989.

Quitério, A., Martins, J., Onofre, M., Costa, J., Mota Rodrigues, J., Gerlach, E., Scheur, C., \& Herrmann, C. (2018). MOBAK 1 Assessment in Primary Physical Education: Exploring Basic Motor Competences of Portuguese 6-Year-Olds. Perceptual and motor skills, 125(6), 1055-1069.

Rámcový vzdělávací program pro základní vzdělávání (RVP ZV). (2021). Praha: MŠMT. Available from: https://revize.edu.cz/files/rvp-zv-2021-s-vyznacenymi-zmenami.pdf

Thorndike, R. L. \& E. Hagen. Test kognitivních schopností (Cognitive Ability Test - CAT). Translation and correstion Vonkomer J. \& J. Jílek. Psychodiagnostika. Brno: Bratislava, 1997.

Veldman, S.L.C., Jones,. RA., Okely, A.D. (2016). Efficacy of gross motor sklil interventions in young children: an updated systematic review. BMJ Open Sport Exerc Med, 2(67). doi:10.1136/bmjsem2015-000067. 